\title{
Mechanical Properties of Recycled Coarse Aggregate Concrete by Partial Replacement of Cement with GGBS and Fly Ash
}

\author{
N. Janardhan, T.Venkaiah, S.Sameer
}

\begin{abstract}
- - in this examinations, it is made to test the power spots of reused coarse mix by methods for inadequate overriding of bond with GGBS and fly ash. on this examination, compressive power, split versatile power and flexural intensity of the reused bonds by techniques for the usage of partial shot of cement with outstanding potential results of GGBS and fly blazing remains. The results got is as differentiated and the regular bond.
\end{abstract}

Key Words - Compressive strength, Split tensile strength, Flexural strength, Recycled aggregate.

\section{INTRODUCTION}

The use of concrete is prolonged to uncommon degree. Concrete exhausts limitless massive measures of sums. for the purpose that sums are non feasible so utilization of proportion of all out might adversy have an effect on the earth. Plus, the improvement and obliteration waste dumping transforms into a giant problem. in this way, it subsequently ends up critical to reuse the development and destruction waste and reuse it.

All development sports activities calls for a couple of materials, as an instance, square, stone, glass, earth, robust, metal, mud, timber, and lots of others. Regardless, the robust stands as the rule development fabric used being advanced companies. Concrete installation itself because the maximum versatile improvement cloth in all the requests of auxiliary making plans because of its immoderate compressive exquisite.what is more, trademark assets are depleting astoundingly due to expansive enthusiasm for brand spanking new upgrades. it's far surveyed that the development commercial enterprise in India makes usage 10-12 million masses of waste each year. The reused all out use in concrete is grabbing predominance all through the world due to the sensible improvement.

India is ultimately delivering development and destruction (C\&D) waste to the song of 23 .seventy five million masses continually and people figures are maximum possibly going to twofold inside the accompanying 7 years. $\mathrm{C} \& \mathrm{D}$ wastes were considered as a benefit in made worldwide locations. Wears down reusing of $C \& D$ wastes have highlighted that if old bond ought to be used in second duration concrete, the aspect must have the specified compressive amazing. Many research works famous that the

\footnotetext{
Revised Manuscript Received on April 12, 2019.

N. Janardhan,Annamacharya Institute of technology and sciences,Tirupati, A.P, India (jana.fire@gmail.com)

T.Venkaiah,Annamacharya Institute of technology and sciences,Tirupati, A.P, India (venkaiah.thummuru@gmail.com)

S.Sameer,Annamacharya Institute of technology and sciences,Tirupati, A.P, India (sameercivil123@gmail.com)
}

compressive first-rate essentially is based upon at the pursued mortar, water ingestion, size of combination, figure robust's excellent, alleviating duration and extent of substitution, degradations gift and condition.

The fundamental roles behind addition in extent of C\&D waste are consistent with the accompanying:

i. Many augmentations and crushed structures.

ii. The structures which are tasteful to apply may be overwhelmed as they now not serving the necessities in current-day circumstance wishes.

iii. constructing waste effects because of from counterfeit failure.

The reusing and reuse of $C \& D$ wastes appear, with the aid of all payments, to be a probable response for every deficiency of unrefined materials and waste dumping troubles. Reusing C\&D waste turn out to be noteworthy usually for the international locations wherein skip of $C \& D$ wastes with heading, disciplines, requests, and so on.

The shortage of speedily available combination and developing price of delivery, which makes constant stress to apply reused substances as substitution to the trademark all out.

The development agency is one of the cash related fragments that are gradually responsible for using normal assets. within the aspect the sports activities related to using using ordinary sources. within the place the sports related to using C\&D waste anticipate a important hobby. the use of one of a kind kinds of waste substances for cutting-edge things is a creating as an normal instance.

Close to the crowning glory of the presence cycle, a fabric breezes up waste, which can be changed into a few other fabric to make new topics or to be used in helper applications.appropriate reusing of waste material is used to make any other cloth of relative tendencies, as such achieving better profitability in its lifestyles cycle.

\section{MATERIAL RESIDENCES}

On this gift exam coarse combination, stable, quality mixture, water, Recycled Coarse mixture, fly blazing remains and GGBS had been used. tremendous all out is gotten from community Swarnamuki flow. common coarse entire is tested from network quarry near Chandragiri. Reused entire is gotten from the squashed sturdy shapes from assistant making plans exploration attention. adjoining consuming water is used for mixing and diminishing. 
Fly powder and GGBS is procured from ASTRRA chemical materials, Chennai.

\subsection{Cement}

Portland stable evaluation 53 is used in this test. Bond is the essential and huge issue in mortar, mortar, concrete, and so on., Cement is an dubious powdered siliceous material that reacts with the stomach settling agent substance found in safety and reacts with the lime in immoderate $\mathrm{pH}$ situation. This reaction will activates the development of additional CSH clasp. The houses are showed up Table 2.1.

Table 2.1. Properties of Cement

\begin{tabular}{|l|l|l|}
\hline S.No. & Property & Result \\
\hline 1. & Fineness & $7 \%$ \\
\hline 2. & Specific gravity & 3.12 \\
\hline 3. & Normal Consistency & $30 \%$ \\
\hline & Setting time(min) & \\
4. & a) Initial & $90 \mathrm{~min}$ \\
& b) Final & $330 \mathrm{~min}$ \\
\hline
\end{tabular}

\subsection{Fine aggregate}

Splendid aggregate i.e., sand is an grains of mineral take into account obtained from the rocks after receives disintegration. It differs from gravels best by using period of the grains or debris, but is not like clays which has organic materials. The homes of amazing combination is shown in Table 2.2.

Table No 2.2 Properties of Fine Aggregate

\begin{tabular}{|l|l|l|}
\hline S.No & Property & Values \\
\hline 1 & Specific Gravity & 2.56 \\
\hline 2 & Fineness Modulus & 2.6 \\
\hline 4 & Grading of Sand & Zone - II \\
\hline
\end{tabular}

\subsection{Coarse Aggregate}

The coarse mix is generous and the least pervious piece of the strong. Coarse absolute can reduce drying shrinkage and Other dimensional adjustments. The coarse complete used for this examination is seemed to IS subtleties. the parts of coarse mix changed into used inside the extent of 60:forty assessed aggregates for instance $60 \%$ of $20 \mathrm{~mm}$ to and forty $\%$ of $12.5 \mathrm{~mm}$. The coarse mix become gone after for its physical homes like precise gravity, fineness modulus, and water maintenance. The investigated effects are displayed in the going with Table 2.3

Table 2.3. Properties of Coarse Aggregate

\begin{tabular}{|l|l|l|}
\hline S.NO & PROPERTY & VALUES \\
\hline 1 & Specific Gravity & 2.61 \\
\hline 2 & Water Absorption & $0.4 \%$ \\
\hline 3 & Fineness Modulus & 6.53 \\
\hline
\end{tabular}

- Reduces bleeding

- Increase time setting

- Improve workability

- Reduces segregation of GGBS are displayed in the Table 2.6

\subsection{Compressive Strength} reliable measure of the quality of concrete.

Fly ash used in this present investigation is obtained from ASTRRA chemicals, Chennai. Properties of fly ash are presented in the following Table 2.4 and Table 2.5

Table 2.4. Physical Properties of Fly Ash

\begin{tabular}{|c|c|}
\hline Colour & White grey \\
\hline Specific gravity & 2.28 \\
\hline Bulk Density & $0.994 \mathrm{gm} / \mathrm{cc}$ \\
\hline
\end{tabular}

Table 2.5. Chemical Properties of Fly Ash

\begin{tabular}{|c|c|}
\hline $\mathrm{SiO}_{2}$ & $59.00 \%$ \\
\hline $\mathrm{Al}_{2} \mathrm{O}$ & $21.00 \%$ \\
\hline $\mathrm{Fe}_{2} \mathrm{O}_{3}$ & $3.70 \%$ \\
\hline $\mathrm{CaO}$ & $6.90 \%$ \\
\hline $\mathrm{MgO}$ & $1.40 \%$ \\
\hline $\mathrm{SO}_{3}$ & $1.00 \%$ \\
\hline $\mathrm{K}_{2} \mathrm{O}$ & $0.90 \%$ \\
\hline $\mathrm{LOI}$ & $4.62 \%$ \\
\hline
\end{tabular}

2.5 Ground Granulated Blast Furnace Slag (GGBS)

The GGBS utilized in this exploration is purchased from AASTRA chemicals, Chennai. floor granulated effect heater slag is the fabric framed whilst liquid iron effect heater slag is fast cooled through submersion in water. The properties

Table 2.6 Properties of GGBS

\begin{tabular}{|l|c|}
\hline Characteristics & $\begin{array}{c}\text { Test } \\
\text { results }\end{array}$ \\
\hline Fineness $(\mathrm{M} / \mathrm{Kg})$ & 390 \\
\hline Specific gravity & 2.85 \\
\hline Particle size & 97.10 \\
\hline Insoluble residue & 0.49 \\
\hline
\end{tabular}

\section{RESULTS AND DISCUSSION}

Compressive strength of concrete is commonly considered as the most reliable property because the strength is usually

The compressive strength values of both natural aggregate and recycled aggregate for different combinations of Fly ash and GGBS are compared and shown in Fig 3.1. 


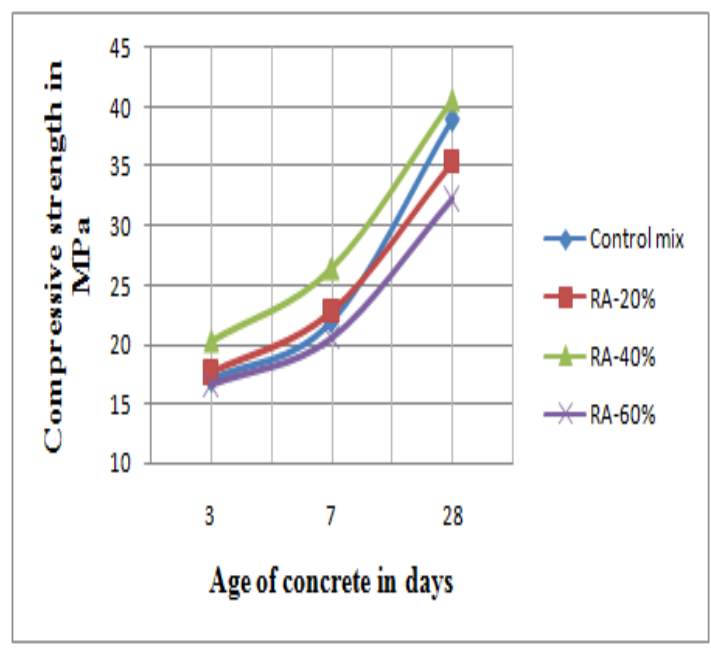

Fig 3.1 Compressive strength of concrete containing recycled coarse aggregate

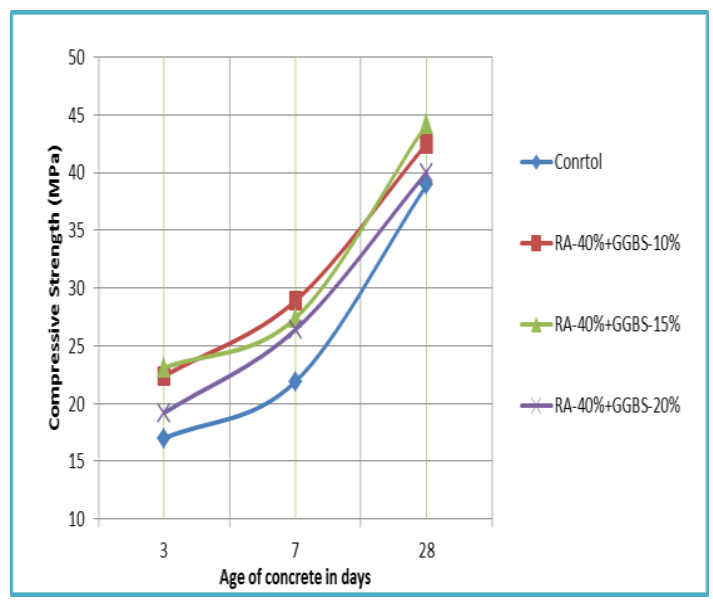

Fig 3.2: Compressive strength of concrete containing RA and GGBS

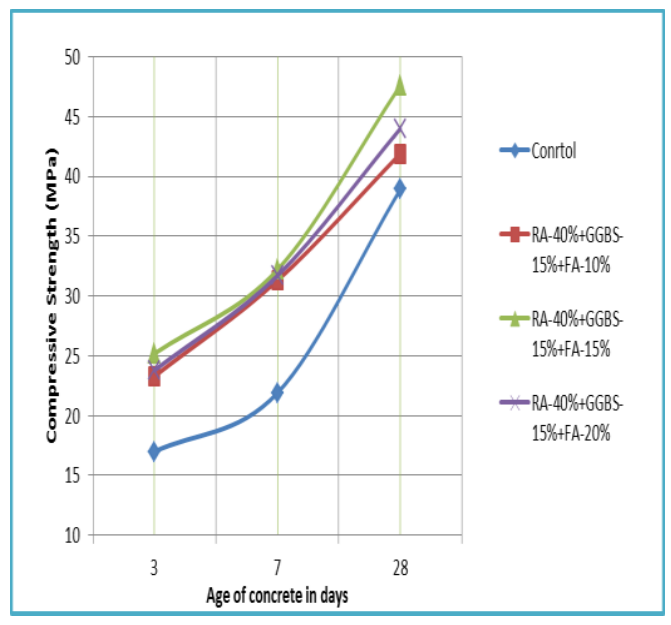

Fig 3.3: Compressive strength of concrete containing RA, GGBS and FA

\subsection{Split Tensile Strength}

This test was carried according to IS 5816-1999. The Split Tensile strength values of both natural aggregate and recycled aggregate for different combinations of Fly Ash and GGBS are compared and shown in Fig 3.4.

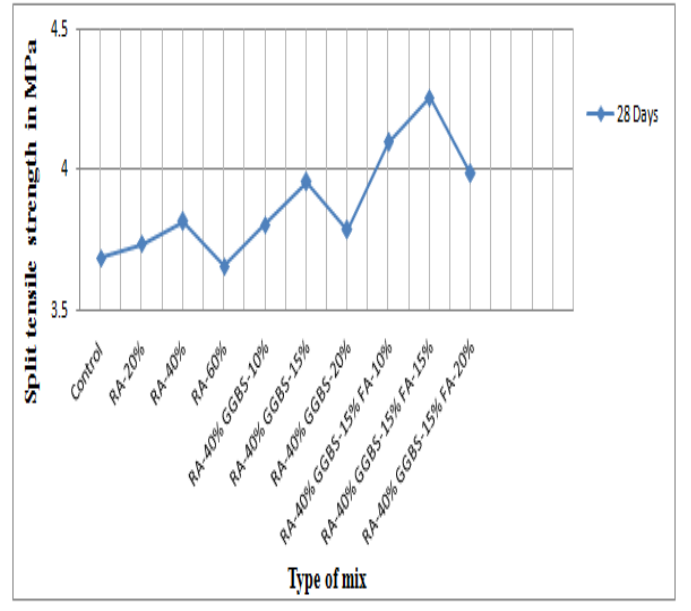

Fig 3.4: Split tensile strength of various concrete mixes

\subsection{Flexural Strength}

The Flexure Strength test was carried according to IS 516-1959. The Split Tensile strength values of both natural aggregate and recycled aggregate for different combinations of GGBS and Fly Ash are compared and shown in Fig 3.5.

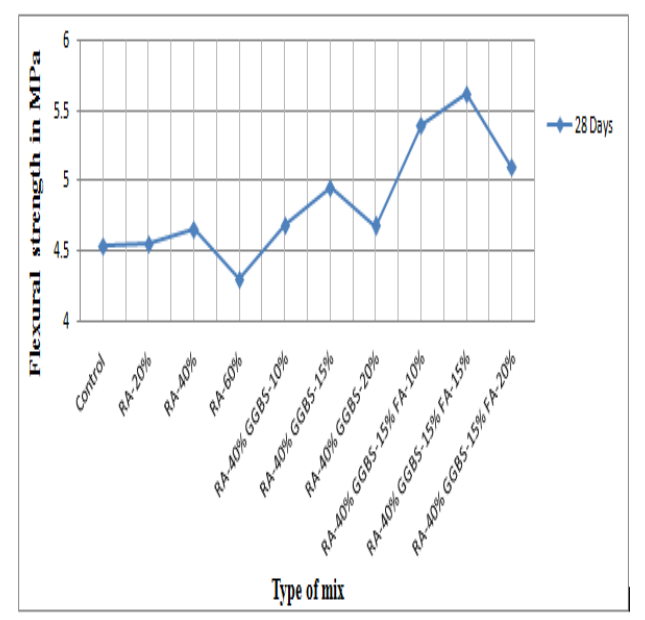

Fig 3.5: Flexural strength of various concrete mixes

\section{CONCLUSIONS}

In a general sense subject to the check aftereffects of the triumphing research, the resulting finishes are drawn.

- The Compressive nature of control Concrete (38.9MPa) has raised by methods for four. $37 \%$ with deficient replacing of typical mix with forty\% Recycled blend (forty.6MPa) and with likewise development the essentialness lessens.

- The Compressive power of control strong will impact by the utilization of 22.three\% while Cement is changed with $15 \%$ of GGBS, $15 \%$ of FA and coarse blend with forty\% of Recycled coarse blend.

- The split Tensile quality, Flexure nature of M30 strong will moreover improvement by strategies for using 15 .forty $4 \%$ and $23.78 \%$ exclusively at choice of forty $\%$ of RCA, $15 \%$ of GGBS and $15 \%$ of FA independently. 
- The imperativeness examples have expansive improvement meanwhile as conversely with control concrete at a most outrageous reliable percent of $40 \%$ Recycled Coarse aggregate, $15 \%$ of GGBS and $15 \%$ of Fly Ash.

- The control improvement in perspective on reuse aggregate, GGBS and Fly Ash is extra while instead of essentialness improvement because of alternative of Recycled mix without any other individual, this is a result of the atom length of GGBS and Fly Ash. these reinforcing materials react with Calcium Hydroxide to shape extra cover material. the pass on of additional spread will extend the blend paste bond results the Recycled Coarse mix Concrete to improve imperativeness houses. as a last item, low quality spots of Recycled Coarse mix Concrete may be advanced through the replacing of bond with $(15 \%)$ GGBS and (15\%) Fly Ash.

\section{REFERENCES}

1. ArlindoGoncalves, Ana Esteves and Manuel Vieria (1990) national Laboratory of Civil Engineering (LNEC), Portugal. impact of reused strong mix on strong quality.

2. Hendriks C.F. likewise, Pieterson H.S. 1998. Concrete: strong in any case likewise practical. court events of overall show on the use of Recycled Concrete blend. Changed through DhirD.ok, Henderson N.A and Limbachiya M.C. 1-18 Thomas Telford, U.ok.

3. PadminiA.k., Ramamurthy okay, Mathews M.S.(2002). "Relative soddenness development by methods for reused blend concrete". magazine. Strong Res., fifty four(five),377384.

4. Ryu J.S. 2002. An exploratory see on the impact of reused aggregate on strong houses, magazine of strong examinations. 54(1):7-12.

5. YuryAdresVillagran-Zaccardi; Claudio Javier Zega; Angel Antonio Di Maio, Chloride Penetrarion and Binding in Recycled concrete, ASCE, 2008.

6. Suraya Hani Adman, Lee Yee Loon, Ismail Abdul Rahman, HamidahMohdSaman, compressive essentialness of reused blend concrete with different dimension of reused mix. schoolTunHuddeinOnn Malaysia (UTHM), 2009.

7. Ishtiyaq Gull, trying out of power of Recycled Waste concrete and its significance, ASCE 2011. 